\title{
Reconquistando o campo perdido: o que Lévi-Strauss deve aos ameríndios ${ }^{1}$
}

\author{
Marcela Coelho de Souza \& Carlos Fausto \\ Pesquisadora associada do Museu Nacional - UFRJ- \\ e professor do Museu Nacional - UFRJ
}

RESUMO: O artigo retoma as pesquisas de campo de Lévi-Strauss no Brasil com base em discussões etnográficas e debates teóricos que sua obra americanista suscitou. O fio condutor é o problema do dualismo, cujo desenvolvimento aqui se acompanha desde os textos inaugurais sobre os Bororo e os Nambikwara até História de Lince (1991). Neste percurso, chama-se atenção para o lugar central dos materiais sul-americanos na obra do autor bem como para a relevância de sua contribuição para a etnologia contemporânea.

PALAVRAS-CHAVE: estruturalismo, dualismo, identidade, populações indígenas.

Só me interessa o que não é meu. Lei do Homem. Lei do Antropófago. (Manifesto Antropófago, Revista de Antropofagia, 1928)

"Quem e o que é Claude Lévi-Strauss?", indagava Curt Nimuendaju em carta escrita a Herbert Baldus em 11 de novembro de 1936:

Eu vi dele, primeiramente, um artigo no [jornal O] Estado [de São Paulo], "Com os selvagens civilizados", que me interessou muito pelo seu posicionamento na questão indígena. Depois vem sua "Contribution à l'étude 
M. C. de Souza \& C. Fausto. Reconquistando o campo perdido...

de l'organisation sociale des Bororo", no JSA [Journal de la Société des Americanistes], onde ele, em poucas páginas, traz material muito valioso, e que chegou para mim como se houvesse sido encomendado. $\mathrm{O}$ que se pode esperar dele a mais no futuro? (apud Welper, 2002)

O autor destas linhas é um alemão que se radicou no Brasil em 1903 e dedicou sua vida à etnografia, à arqueologia e ao indigenismo, encarnando, no imaginário da etnologia brasileira, a figura do seu primeiro pesquisador de campo. Batizado "Nimuendaju” pelos Guarani de São Paulo em 1906, morreu em 1945 no rio Solimões, entre os Tikuna. Em 1936, Nimuendaju era o principal especialista em povos indígenas situados no Brasil, uma referência para todos os antropólogos europeus, inclusive Lévi-Strauss que, no ano seguinte, o convidaria, sem sucesso, para fazer parte de sua expedição à Serra do Norte ${ }^{2}$. Em 13 de janeiro de 1937, Nimuendaju voltaria a escrever a Baldus sobre Lévi-Strauss:

Notável é que o homem, como o senhor escreve, que só recentemente passou para a etnologia, tenha se inteirado em tão pouco tempo de uma maneira tal, que ele compreendeu com tanta precisão as condições sociológicas dos Bororo, que de fato não são simples. Se eu penso em como lutei por seis anos com a sociologia dos Canelas, chama a atenção a forma concisa da apresentação.

Como explicar essa admiração de Nimuendaju, um homem calejado por décadas de pesquisa, por um trabalho baseado em tão breve permanência em campo? Reconhecido no meio acadêmico antes por sua obra teórica do que por (e, em certo sentido, apesar de) sua experiência de campo, Lévi-Strauss seria para alguns um viajante-filósofo, não um etnógrafo; para outros, mais impacientes, nem isto, como fez questão de marcar Luis de Castro Faria, membro da expedição à Serra do Norte: 
Revista de Antropologia, São Paulo, USP, 2004, v. 47 No 1.

Cette expédition est le prix que Claude Lévi-Strauss a payé pour être reconnu comme un véritable ethnologue. Mais (...) il n'avait pas le "physique du rôle". Il avait des difficultés à communiquer, et ça l'ennuyait d'être aussi loin de la civilisation, de son confort. (Libération, 1/9/1988)

Desmistificar o homem e sua aventura pode ter lá sua função e sua verdade. Tristes tropiques contém não apenas a tristeza dos trópicos mas, também, uma sensibilidade particular que detesta viagens, mesmo quando as empreende, e exploradores, mesmo quando se é um deles. Quem se prende, contudo, ao quixotismo de Lévi-Strauss, perde de vista sua faculdade de combinar uma visão geométrica, capaz de apreender grandes estruturas, com um olhar minucioso, capaz de atentar para os detalhes etnográficos, como se a memória operasse à maneira de uma câmera fotográfica dotada de lente zoom, os olhos deslizando da grande-angular à teleobjetiva, passando do micro ao macro e produzindo uma série de fotogramas em diferentes escalas. Essa faculdade não é cinematográfica; ela tende a abolir a continuidade do movimento, os espaços intercalares. Não que seja avessa a toda dinâmica, mas esta só pode ser reconstituída a posteriori, como na montagem de uma seqüência a partir de stills fotográficos, na qual cada instantâneo tem ao mesmo tempo sua forma própria e sua forma transformada no instantâneo seguinte. É essa a faculdade que Lévi-Strauss pôs em campo entre os Kadiwéu, os Bororo, os Nambikwara, os Tupi-Kawahib, nos anos 1930, e alcançou plenitude nas Mythologiques ${ }^{3}$. Nimuendaju soube reconhecer esse fato, talvez porque tenha lutado a vida toda com os detalhes e tenha-lhe faltado uma grande angular, uma ausência algo irônica para quem começou a vida como mecânico óptico na fábrica da Zeiss em Jena (Welper, 2002, p. 32).

Neste artigo, queremos regagner le terrain perdu de Lévi-Strauss. Não se trata de saber o que ele fez ou deixou de fazer, nem de julgar os resultados empíricos de suas pesquisas. O que nos interessa é traçar o campo 
M. C. de Souza \& C. Fausto. Reconquistando o campo perdido...

de idéias e de problemas que essa experiência legou a Lévi-Strauss e, por meio dele, aos pesquisadores que vieram depois. Resgatar "o que LéviStrauss deve aos índios" não consiste, pois, em dar a cada um a sua parte, mas em sublinhar os aspectos da obra americanista levistraussiana que, pela sua capacidade contínua de animar o debate contemporâneo, testemunham as lições que o antropólogo soube tirar de seu encontro com os índios sul-americanos.

Tomaremos como fio condutor o tema do dualismo. Invertendo a ordem cronológica de suas viagens, começaremos pelos Nambikwara, que estão, em mais de um sentido, no começo: seja por terem passado ao imaginário da antropologia política como representando o grau zero da autoridade (e para Lévi-Strauss de toda socialidade), seja por representarem na obra sociológica do autor a forma mais simples e pura do princípio de reciprocidade. Em seguida, passaremos aos Bororo, e ao desafio posto pela complexificação da fórmula dualista, para a partir daí acompanhar os desdobramentos dessa questão na obra de Lévi-Strauss, focalizando a dialética entre simetria e hierarquia, entre diametralismo e concentrismo, até chegarmos a Histoire de Lynx e à formulação mais americanista do problema do dualismo.

\section{Arcaísmos}

A experiência mais longa de Lévi-Strauss junto a um grupo indígena deu-se entre junho e setembro de 1938, durante a estação seca, na região noroeste do estado do Mato Grosso, onde manteve contatos com bandos nambikwara setentrionais que circulavam na área de influência da missão religiosa de Utiariti. Com base nessa experiência, Lévi-Strauss dedicou aos Nambikwara um conjunto de artigos (1944a, 1946, 1947), sua tese complementar (1948a), um capítulo no Handbook of South 
Revista de Antropologia, São Paulo, USP, 2004, v. 47 no 1.

American Indians (1948b), além de parte de Tristes tropiques (1955). Curiosamente, nenhum destes textos foi republicado nos volumes de $A n$ thropologie Structurale, assim como não o foram artigos mais gerais datados do mesmo período, como o famoso texto sobre a guerra e o comércio (1976[1942]) e outro, menos conhecido, sobre o parentesco sul-americano (1943) - todos eles anteriores à deriva da antropologia em direção à língüística estrutural anunciada por Lévi-Strauss em 1945. O campo entre os Nambikwara, no entanto, reaparece nos artigos sobre o arcaísmo (1974[1952a]) e o xamanismo (1974[1949]), assim como em Les structures elémentaires de la parenté (doravante SEP), em que desempenha papel central na conceitualização do casamento de primos.

A literatura antropológica reteve, dos trabalhos sobre os Nambikwara, duas imagens principais: de um lado, a do bimodalismo econômico e quase-nomadismo; de outro, a da organização política simples, na qual o chefe não seria senão um servo do grupo. Os Nambikwara passaram à imaginação da disciplina como um povo extremamente móvel, praticando uma horticultura muito simples, ora vivendo em aldeias semipermanentes, ora se organizando em bandos nômades reunidos em torno de líderes desprovidos de poder e de bens, cujo único privilégio seria a poligamia. Pesquisadores posteriores colocaram em cheque as descrições de Lévi-Strauss sobre a economia nambikwara, sugerindo que eles, primeiro, não são sazonalmente nômades, pois a maior mobilidade ocorre em períodos microssazonais e acompanha o ritmo dos trabalhos agrícolas, e, segundo, que eles vivem em aldeias permanentes e possuem uma horticultura relativamente diversificada ${ }^{4}$. Price (1981) sugeriu ainda maior variabilidade na chefia nambikwara e maior autoridade de seus líderes, nuançando o modelo de Lévi-Strauss, que Clastres generalizaria à quase totalidade das terras baixas sul-americanas (generalização que hoje é objeto de muitas críticas). 
M. C. de Souza \& C. Fausto. Reconquistando o campo perdido...

Para Lévi-Strauss, no entanto, a mobilidade e acefalia nambikwara refletiam uma situação histórico-etnográfica específica, ainda que privilegiada por ilustrar o limite mínimo da organização social e da autoridade política. Essa elementaridade dos Nambikwara, central para a reflexão de Lévi-Strauss e para a emulação de Rousseau, não resultava da projeção de um imaginário primitivista sobre a realidade etnográfica. Afinal, o campo entre os Nambikwara e os Bororo conduziu Lévi-Strauss a uma das críticas mais importantes do primitivismo a-histórico que marcara o esquema evolutivo do Handbook of South American Indians crítica que ele ensaiara em um artigo de 1944 (1994b) (em que respondia a Lowie [1941] sobre o caráter adventício ou não da organização social jê) e desenvolveu em "La Notion d'Archaïsme en Ethnologie" $(1974[1952 a])^{5}$. Curiosamente, nem Aspelin nem Price citam esses artigos, nos quais Lévi-Strauss coloca em dúvida a simplicidade original dos povos do Brasil Central.

$\mathrm{O}$ argumento sobre o falso arcaísmo é moderno, apesar da linguagem da época. Lévi-Strauss marca distância em relação à idéia de que as sociedades como a Nambikwara ou Bororo possam ser tratadas como sobrevivências de um estágio arcaico da humanidade. Crê-lo, diz o autor, é conferir a essas sociedades

l'exorbitant privilège d'avoir duré e de n'avoir point d'histoire (...) L'archaïsme veritable est l'affaire de l'archéologue et du préhistorien, mais que l'ethnologue, voué à l'étude de sociétés vivantes et actuelles, ne doit pas oublier que, pour être telles, il faut qu'elles aient vécu, duré, et donc changé. (1974[1952a], p. 115 e 126)

Toda sociedade está na história, ainda que nem todas elas façam a mesma coisa com esta história - um ponto que os críticos das noções de quente e frio fizeram questão de esquecer. 
Revista de Antropologia, São Paulo, USP, 2004, v. 47 no 1.

Assim, se Lévi-Strauss equivoca-se sobre a importância relativa da horticultura entre os Nambikwara, ele não os constrói como um exemplar típico de sociedades caçadoras-coletoras, mas como o produto de uma história regressiva ${ }^{6}$. Apesar de historicizar o problema, Lévi-Strauss construiu o argumento regressivo supondo a associação inequívoca entre mobilidade e privação, reproduzindo uma representação sobre a mobilidade indígena, enraizada desde o século XVI, para a qual caça e coleta são signos necessários de insegurança e escassez, enquanto a agricultura, de estabilidade e fartura. Nas últimas décadas, alguns autores relativizaram essa representação para populações de floresta, por meio de estudos quantitativos (Hill \& Hawkes, 1983; Hawkes et al., 1982), e de caráter histórico-etnográfico (Fausto, 2001; Rival, 1998, 2002).

O objeto de Lévi-Strauss, certo, eram os povos do cerrado, um ambiente que ele reputava estéril, incapaz de gerar novas invenções culturais. Daí ele negar a existência de uma "culture de la savane”, a qual não seria senão "une imitation impuissante de la culture forestière" (1974 [1952a], p. 124). Ver a savana com os olhos da floresta (ou do litoral) foi uma constante na história da colonização do Brasil, uma visão que estava em continuidade com aquela dos Tupinambá, habitantes da costa atlântica no século XVI, que desprezavam seus vizinhos do interior, chamados genericamente de Tapuia, a maioria deles povos de língua macro-Jê. Ao pensar o cerrado como oferecendo uma "influence negative" e ao insistir, na esteira de Nimuendaju, na complexidade dos sistemas sociais dos povos Jê e Bororo, Lévi-Strauss colocara-se diante de um problema que ele buscou resolver com a noção de falso arcaísmo: a regressão aparece como resposta para o enigma posto pela conjunção de um ambiente pobre, uma tecnologia simples e uma organização social complexa. Trabalhos mais recentes sobre a etno-ecologia e o manejo do cerrado por povos indígenas sugerem, contudo, a existência de um conhecimento específico e sofisticado, que não pode ser atribuído a uma 
M. C. de Souza \& C. Fausto. Reconquistando o campo perdido...

versão "appauvrie et diminuée de la culture forestière" , sugerindo, ao contrário, um desenvolvimento autóctone e não regressivo, quando não uma explosão de complexidade em um determinado momento da história (Wüst, 1998; Wüst \& Barreto, 1999).

Se o contraste entre pobreza da savana e riqueza da floresta é um legado do imaginário de Handbook of South American Indians - organizado em torno de duas oposições axiais: terras altas versus terras baixas e floresta versus campos, com a costa aparecendo como zona híbrida de possibilidades múltiplas (Steward, 1950; Steward \& Faron, 1959) -, é preciso lembrar que Lévi-Strauss desde o início criticara o caráter a-histórico desta tipologia e que jamais aceitou sua tradução em uma teoria determinista do ambiente como fator estritamente limitante ao desenvolvimento das culturas da região (Meggers, 1954, 1971; Gross, 1975). Daí Lévi-Strauss julgar o novo imaginário proposto pela arqueologia dos anos 1980 e 1990 (Roosevelt, 1980; 1993) como um retorno às suas intuiçôes, intuiçôes que giram, uma vez mais, em torno do problema do arcaísmo:

Déjà en 1935, chez les Bororo, j'étais frappé par des traditions indigènes sur les grands villages du temps passé, si densément peuplés que les maisons formaient plusieurs cercles concentriques. Quelques années plus tard, il m'apparaissait que les Nambikwara n'offraient pas l'image d'une structure sociale élémentaire, vestige de temps archaïques, mais que les vicissitudes de l'histoire les $y$ avaient contraints. Je défendis vainement cette thèse contre Lowie et le P. Cooper à l'époque de l'élaboration du Handbook of South American Indians. (Lévi-Strauss, 1993, p. 8) 
Revista de Antropologia, São Paulo, USP, 2004, v. 47 no 1.

\section{Protodualismo}

Se a estrutura social nambikwara não aparece em Lévi-Strauss como um vestígio de tempos arcaicos, há certamente um sentido em que ela é retratada como "elementar". Ainda que ele não os tome como um fato natural, mas como produto de uma história específica, os Nambikwara ocupam em sua obra lugar equivalente ao do estado de natureza na filosofia política, o que é expresso com clareza em Tristes tropiques:

J'avais cherché une société réduite à sa plus simple expression. Celle des Nambikwara l'était au point que j'y trouvais seulement des hommes. (1955, p. 284)

E mais adiante:

jétais allé jusqu'au bout du monde à la recherche de ce que Rousseau appelle "les progrès presque insensibles des commencements". (idem)

Esse progresso dos começos, Lévi-Strauss vislumbra em seu encontro com duas "hordas" nambikwara, de dialetos distintos, aliadas por meio de uma convenção que fazia dos homens de uma "cunhados" dos homens da outra (e fazia das respectivas esposas "irmãs", e vice-versa), de modo que na geração seguinte os casamentos inter-hordas se adequariam à assimilação entre afins e cruzados, característica de seu sistema de parentesco. Se os dois grupos assim unidos guardassem a memória de sua dupla origem, raciocina Lévi-Strauss, mantendo por exemplo a separação entre os respectivos acampamentos, estariam desta maneira lançadas as bases de um sistema de metades exogâmicas (1943, p. 1-3; 1948a, p. 79; 1955, p. 351; 1962, p. 74; 1967[1949], p. 78-9). O caso - por demais anedótico, reconhece, para que se possa sobre ele fundar uma teoria da origem das organizações dualistas - aparece-lhe entretan- 
M. C. de Souza \& C. Fausto. Reconquistando o campo perdido...

to como um em que, nas palavras que toma emprestado de Lowie, "the characteristic features of the sib organization are in some measure prefigured among sibless tribes" (Lowie, 1919, p. 28 apud Lévi-Strauss, 1943, p. 403).

No sentido que Lévi-Strauss atribuirá a essa “prefiguração” está a chave de sua solução para o problema da relação entre organização dualista, casamento de primos cruzados e terminologias classificatórias simétricas. Esse é um momento crucial das SEP: ele faz a ponte entre a dedução da proibição do incesto, como regra universal na origem da cultura, e a interpretação de sistemas concretos em termos de estruturas elementares de troca matrimonial; isto é, a ponte entre a teoria estruturalista do parentesco e a teoria restrita da aliança de casamento (Dumont, 1971, p. 91). A importância excepcional do casamento de primos, diz LéviStrauss, reside na arbitrariedade, do ponto de vista biológico, da divisão dos primos em cônjuges prescritos e proibidos (1967[1949], p. 142), que fica assim a requerer uma explicação de outra ordem: "verdadeiro experimentum crucis do estudo das proibições matrimoniais" (idem, p. 143), a instituição manifestaria com especial clareza a onipresença da reciprocidade, mesmo na ausência de fórmulas explícitas de aliança entre grupos. Demonstrando que "la notion de reciprocité permet donc de déduire immédiatement la dichotomie des cousins" (idem, p. 152), LéviStrauss oferece uma explicação estrutural para um fenômeno extremamente difundido - as terminologias classificatórias simétricas - cuja interpretação fora até então dominada por especulações evolucionistas ou historicistas, além de estender o alcance de sua demonstração, já que a distribuição destes sistemas de classificação é mais ampla que a da norma matrimonial.

A importância teórica do casamento de primos, que faz dele um dos temas dominantes na primeira parte das SEP, não é porém suficiente para garantir o lugar de sistemas como o dos Nambikwara na análise da 
Revista de Antropologia, São Paulo, USP, 2004, v. 47 no 1.

troca restrita, que se concentra nas seções australianas. Isto porque, embora equivalentes do ponto de vista de seu valor funcional (estabelecer um sistema de reciprocidade), o casamento de primos e a organização dualista diferem consideravelmente quanto à sua estrutura, exemplificando uma distinção de importância na teoria da aliança entre o método das relações e o método das classes, entre a delimitação automática dos cônjuges possíveis pela constituição de uma classe e a "determinação de uma relação, ou conjunto de relações, que permitem dizer, em cada caso, se o cônjuge visado é desejável ou excluído" (1967[1949], p. 139).

O lugar marginal dos Nambikwara nas SEP se explica, assim, pelo caráter incoativo de seu dualismo puramente relacional. Aquém das estruturas elementares (Viveiros de Castro, 1993, p. 154), só poderiam ocupar o lugar de fundamento teórico, jamais exemplificar o funcionamento sociológico real dessas estruturas. Daí decorre a dificuldade, sentida por muitos etnólogos nas décadas de 1950 e 1960, em analisar os sistemas amazônicos similares ao dos Nambikwara. Se os instrumentais analíticos da teoria da descendência eram inadequados à região, a teoria de Lévi-Strauss tampouco parecia muito útil. Curiosamente, a aclimatação da teoria da aliança à Amazônia acabou mediada por uma passagem pela Índia do Sul, pelos trabalhos de Louis Dumont sobre os povos dravidianos (1953; 1957; 1983). As análises de Dumont, bem como sua crítica da passagem do local ao global nas SEP (Dumont, 1971), libertaram a teoria da aliança da linguagem das "classes", abrindo caminho para a extensão do conceito de estrutura elementar (ou, pelo menos, de "aliança de casamento" ou de "troca simétrica") para além do universo dos sistemas unilineares, de modo a incluir também sistemas fundados exclusivamente no método das relações (Overing Kaplan, 1975; Rivière, 1969; 1973; Becker1969; Viveiros de Castro, 1993). As conseqüências desse movimento, fundamental para a análise dos sistemas de parentescos amazônicos, foi, no entanto, muito além do 
M. C. de Souza \& C. Fausto. Reconquistando o campo perdido...

próprio parentesco, pois permitiu que se recuperasse uma intuição inaugural de Lévi-Strauss, em cuja origem, mais uma vez, está o célebre encontro de dois bandos nambikwara e sua busca de termos para expressar um relacionamento antes inexistente.

As páginas finais do artigo "The Social Use of Kinship Terms among Brazilian Indians" (1943) resumem a questão. Ao aproximar os Nambikwara dos Tupi quinhentistas, Lévi-Strauss focaliza a troca matrimonial, em especial o casamento de primos cruzados, mas vai além, discutindo os termos que, utilizados por indivíduos sem uma relação prévia de parentesco, permitem estabelecer um relacionamento. Esses termos, que a literatura posterior mostraria serem numerosos, exprimiriam para o autor um "special 'brother-in-law' relationship" que funcionaria como dispositivo de abertura do universo do parentesco, servindo para estabelecer relações sociais mais amplas:

When the technical problem of establishing new social relationship is put up to the Indians [Nambikwara], it is not the vague "brotherhood" which is called upon, but the more complex mechanism of the "brother-in-law" relationship. (1943, p. 407, n. 22)

Ao final do texto, após analisar as semelhanças e diferenças entre o cunhadio ameríndio e o compadrio euroamericano, Lévi-Strauss conclui que "the outstanding character of the 'brother-in-law' relationship [is] a specific feature of South American sociology". Recusando a separação entre sociedade e cultura, cosmologia e sociologia, a literatura etnológica, a partir do final dos anos 1960, tiraria todas as conseqüências dessa intuição de Lévi-Strauss, em um movimento no qual a categoria da afinidade ganharia progressivamente em compreensão e extensão. Tomada inicialmente como mecanismo interno de constituição de grupos locais (Rivière, 1969; Overing Kaplan, 1975), a afinidade apareceria, em se- 
Revista de Antropologia, São Paulo, USP, 2004, v. 47 no 1.

guida, como dispositivo relacional que viabiliza e organiza as relações extralocais, articulando pessoas e coletivos para além do parentesco (ver, em especial, Albert, 1985; Descola, 1981), e, finalmente, como idioma e esquema da relação entre o Mesmo e o Outro, entre identidade e diferença (Descola, 1992; Viveiros de Castro, 1993; 2001).

A elaboração da afinidade como "fenômeno político-ritual, exterior e superior ao plano englobado do parentesco" (Viveiros de Castro, 1993, p. 181), veio ao encontro de uma série de estudos sobre os fenômenos da guerra e do canibalismo, em que a posição de Outro - determinada pela alteridade e inimizade - é, nos contextos etnográficos específicos, preenchida por diferentes figuras: cunhados e inimigos reais ou imaginários, humanos ou não-humanos relacionados como afins. Este Outro surge, assim, como a determinação do Si, determinação positiva e necessária à constituição e ao funcionamento dos sistemas sociocosmológicos indígenas. Foi justamente a recusa da oposição social e cultural que permitiu a extensão das figuras da afinidade para além do local e do estritamente humano, movimento que desembocou no debate em torno das noçôes de animismo e perspectivismo (Descola, 1986; 1992; Arhem, 1993; Viveiros de Castro, 1996a; Lima 1996). Ao afirmar que para os ameríndios as relações sociais ultrapassam o universo dos humanos, a etnologia amazônica fez da acusação de idealismo - invectiva lançada por africanistas de tradição marxista aos americanistas de inspiração estruturalista - uma virtude. Desse duplo movimento - a adoção de uma perspectiva antiidentitária e relacional, e a recusa da distinção forte entre ideal e material - resultou uma etnologia que, com um pé nas SEP e o outro nas Mitológicas, procura hoje repensar a oposição central que estrutura ambos os trabalhos: aquela entre natureza e cultura. Nesse sentido, também a "anthropologie de la nature" (Descola, 2001), e não só a antropologia do parentesco americanista, deriva do cunhadio nambikwara. 
M. C. de Souza \& C. Fausto. Reconquistando o campo perdido...

\section{Multidualismo: hierarquia e reciprocidade}

Se a compreensão das sociedades de tipo nambikwara seguiu o caminho que descrevemos acima, o multidualismo dos Jê e Bororo, entretanto, pôs problemas de outra ordem. Se, tanto num caso como no outro, o princípio de reciprocidade responde pela integração do grupo, esta integração obedece a ritmos diferentes na Amazônia e no Brasil Central. No universo do protodualismo, é a extensão da linguagem do parentesco - mais precisamente, da afinidade - ao plano político que cumpre essa função. A percepção do significado sociopolítico da relação de afinidade - epitomizado na figura do "cunhado" - desempenha um papelchave na conceitualização por Lévi-Strauss do casamento de primos: é esta dimensão sociopolítica que, ao projetar-se além da imediatez dos laços intracognáticos, sob a forma da afinidade fictícia, confere à fórmula egocêntrica um efeito sociológico supra-individual, permitindolhe operar como dispositivo integrativo, conforme o exemplo dos dois bandos nambikwara, ou da instituição do "compérage" entre os Tupi históricos (Lévi-Strauss, 1943; cf. 1967[1949], p. 503). O grupo emerge, nesses casos, como produto de uma síntese local mediada pelo idioma do parentesco.

No caso centro-brasileiro, ao contrário, a integração social estaria desde o início dada: é efetivamente difícil não ver suas aldeias circulares como um diagrama de partes, todos e conexões postos por uma sociologia indígena, um plano normativo que, nas palavras de J. Crocker (a propósito dos Bororo),

sets out the arrangement of the (...) corporate groups in the village circle; stipulates, to a degree, their internal differentiation; and relates the whole to the natural and spiritual universe. (1979, p. 252) 
Revista de Antropologia, São Paulo, USP, 2004, v. 47 no 1.

O contraste entre uma forma de sociabilidade pré-dada (sob o risco de dissolução) e outra inacabada (e inacabável) está implícito na estratégia de comparação regional, fundada na oposição entre eflorescência estrutural das sociedades centro-brasileiras e o minimalismo sociológico amazônico. Enquanto o último caso se presta à desconstrução do conceito de Sociedade de que se ocupa boa parte da antropologia contemporânea, o primeiro nos confronta - ao menos, à primeira vista com uma (hoje) incômoda versão nativa de nossa visão do social como totalidade.

Desse ponto de vista, o problema "técnico" colocado pelas sociedades centro-brasileiras seria não o do estabelecimento de novos laços sociais, mas o da prevenção da dissolução do "todo" em seus elementos componentes. Para os pesquisadores do Projeto Harvard-Museu Nacional $^{8}$, o faccionalismo aparecerá como o sintoma de disfuncionalidade por excelência, e a capacidade de prevenir seu desenvolvimento como prova da vitalidade das instituiçôes e da cultura do povo em questão. Já para Lévi-Strauss, o risco de decomposição resultaria do que podemos chamar de efeitos endogâmicos do multidualismo.

O caminho que levou Lévi-Strauss a essa discussão passa pelo sul do atual estado do Mato Grosso, onde, em 1936, ele travou contato com os Bororo, povo de língua Macro-Jê. Recém-saído dessa primeira experiência de campo, Lévi-Strauss publicou seu primeiro texto etnológico, "Contribuição ao estudo da organização social dos índios Bororo", que tanto impressionou Nimuendaju. Baseado em uma estada de menos de dois meses na aldeia de Kejara, trata-se de uma das primeiras descriçóes antropologicamente informadas desse povo 9 . O registro etnográfico do artigo em nada antecipa os arrojos especulativos que, nos anos 1950, marcarão sua reflexão sobre as culturas indígenas centro-brasileiras. Recorrendo à distinção que ele próprio irá fazer mais tarde entre um "modelo teórico simplificado" da estrutura social bororo, o "plano desta ou 
M. C. De Souza \& C. Fausto. Reconquistando o campo perdido...

daquela aldeia particular", e um "modelo sincrético consolidando, num esquema único, informações obtidas junto a diversas fontes indígenas" (1964, p. 48), pode-se dizer que, em 1936, Lévi-Strauss se mantém mais próximo ao plano de uma aldeia particular, enquanto que as hipóteses dos anos 1950 irão, pelo contrário, manipular "modelos teóricos simplificados" - excessivamente simplificados, quando não fictícios, dirão alguns críticos. Entre esses dois momentos, há, de um lado, a leitura por Lévi-Strauss dos trabalhos dos padres salesianos sobre os Bororo, publicados na década de 1940 (Colbacchini \& Albisetti, 1942; Albisetti, 1948), de outro, a elaboração das SEP, que envolve a reflexão sobre os sistemas jê descritos por Nimuendaju. A leitura de Colbacchini e Albisetti permite-lhe impor maior ordem ao próprio material; é apenas a partir dela, por exemplo, que o sistema clânico octagonal adquire a nitidez com que passará a figurar nos diferentes modelos subseqüentes ${ }^{10}$.

Lévi-Strauss irá, mais tarde, criticar os autores da Enciclopédia Bororo (Albisetti \& Venturelli, 1962) por adotarem um modelo sincrético, apontando sua tendência a censurar indicações inconsistentes ou contraditórias, como se em busca de "uma verdade única e absoluta que, entre os Bororo, provavelmente nunca existiu” (Lévi-Strauss, 1964, p. 50). A construção de um modelo propriamente teórico não dependeria, por sua vez, de uma tal arbitragem. Essa distinção permite tratar um dos aspectos salientes da carreira do "problema bororo" na etnologia americanista; a saber, a proliferação de modelos (tanto antropológicos como nativos) da estrutura social deste povo, tal como expressos nos planos espaciais de suas aldeias. Essa proliferação é etnograficamente significativa: isto é, diz algo não apenas sobre a empresa antropológica, mas sobre as realidades indígenas. Ao tomá-la a sério, Lévi-Strauss desenvolve algumas de suas idéias mais fecundas para a etnologia posterior.

O esquema clássico da organização social bororo (que corresponde, por exemplo, ao "modelo simplificado" que aparece em $O$ cru e o cozido) 
Revista de Antropologia, São Paulo, USP, 2004, v. 47 no 1.

é o de uma aldeia bipartida por um eixo leste-oeste, composta de uma metade norte e uma metade sul, subdivididas em quatro clãs cada uma. A casa dos homens, no centro, reproduz (e inverte) internamente a mesma divisão. Metades e clãs são exógamos, matrilineares e conectados por complexas relações rituais. Há, todavia, aspectos hierárquicos nessa organização, que (entre outros elementos) complexificam a descrição. Tais aspectos preocupam desde cedo Lévi-Strauss, que, no mesmo ano em que publica "On dual organization in South America" (1944b), no qual sugere pela primeira vez o caráter adventício das organizações dualistas centro-brasileiras, coloca-se a questão da relação entre reciprocidade e hierarquia entre os Bororo (1944c).

A questão é inicialmente posta em termos da natureza simétrica ou assimétrica das relaçôes entre as metades ${ }^{11}$, mas acaba por se dirigir para outro aspecto do sistema bororo: o de uma oposição adicional entre os "de cima” e os “de baixo", sobreposta à divisão original. Em 1936, LéviStrauss descrevera a aldeia de Kejara como dividida, por um eixo nortesul suplementar, em um segundo par de metades: "de l'amont" (Cabogewoge) e "de l'aval" (Cebegewoge) (1936, p. 271-2). Algo similar fora apontado para os Bororo do Rio das Garças por Colbacchini em 1925, mas a interpretação posterior da Enciclopédia Bororo, que se tornará canônica, é de que a oposição em jogo expressa uma partição interna de cada clã em dois "subclâs": o dos "superiores" e o dos "inferiores", admitindo ainda uma categoria intermediária ("os do meio"), de estatuto bastante problemático. Embora essa interpretação dos salesianos tenha sido tomada em alguns casos como a última palavra sobre a questão (Crocker, 1967, p. 112; Maybury-Lewis, 1960, p. 23; Zerries, 1976, p. 102), a etnografia posterior sugere cautela (Viertler, 1976; Fabian, 1992). Lévi-Strauss vai, de sua parte, continuar sustentando a verossimilhança de suas observações iniciais, enfatizando o risco existente em se sacrificar, em nome da coerência do modelo, a diversidade das variantes 
M. C. de Souza \& C. Fausto. Reconquistando o campo perdido...

locais e das interpretações nativas $(1964 ; 1973)^{12}$. Ele próprio, entretanto, acabará por escorar-se na interpretação dos salesianos para formular uma de suas mais conhecidas hipóteses sobre os Bororo: a de que as complexidades da exogamia esconderiam uma realidade endogâmica.

Essa hipótese, que se encontra em Tristes trópicos, remonta parcialmente a dados registrados por Lévi-Strauss em 1936. Ele discernira, então, um sistema de "uniões preferenciais" entre unidades formadas por classes de nomes pessoais (ou títulos) pertencentes ao clā, diferenciadas em termos das riquezas clânicas (Lévi-Strauss, 1936, p. 278-81). Mais tarde, munindo-se das indicaçôes de Albisetti (1948), ele identifica tais unidades aos subclãs da Enciclopédia Bororo, e constrói um modelo segundo o qual as unióes preferenciais se dariam exclusivamente entre subclãs de mesmo rank:

Si cette description était exacte (...) on voit que le schéma classique des institutions bororo s'effondrerait. Quelles que soient les préferences matrimoniales qui unissent entre eux certains clans, les clans proprement dits perdraient toute valeur fonctionelle (...) et la société bororo se réduirait à trois groupes endogames (...) qui constitueraient vraiment trois sous-sociétés. (Lévi-Strauss, 1974[1952b], p. 142)

A natureza das subdivisões clânicas bororo - e sua expressão concreta no plano residencial (ver especialmente Viertler, 1976, e Caiuby Novaes, 1986) - é um problema muito complexo. Os nomes ou classes de nomes a que aludia Lévi-Strauss em 1936 correspondem a unidades referidas como i-e ("nome"), e que Crocker glosa ora como "linhagem" ora como "name-set". Os "subclās" consistem em agregados de i-e. Mas nada obriga (ou autoriza) a conceber essa agregação em termos segmentares, como se $i-e$ e subclãs designassem segmentos embutidos em ordens de inclusão sucessivas, produzidos pela projeção de um mesmo 
Revista de Antropologia, São Paulo, USP, 2004, v. 47 no 1.

princípio (a matrilinearidade ou a uxorilocalidade) por meio dos diferentes níveis. Pelo menos, é o que sugere a etnografia posterior, na qual se constata que a tripartição "de baixo/do meio/de cima” (Xebegiwuge/ Boedawuge/Xobugiwuge) está longe de esgotar o repertório de contrastes categoriais mobilizados para fixar diferenças no interior de cada clã. Vários outros, inclusive, já haviam sido identificados por Lévi-Strauss em 1936: (irmãos) mais velhos/mais novos, preto/vermelho, além de distinções que correspondem aos emblemas (os aroe) específicos associados a diferentes segmentos de um mesmo clã. Não está clara, na literatura, a relação entre essas diferentes oposições; o que é certo é que esses contrastes, justamente, não se recobrem. E isto não apenas na prática, mas também no plano do modelo: nem todos são aplicados (ou aplicáveis) simultaneamente em todos os clãs, e, mesmo quando o são, não designam divisões equivalentes quanto a sua extensão ou função.

A conexão entre esses contrastes e as alianças matrimoniais, todavia, parece segura (Viertler, 1976, p. 172). Assim, o problema com a hipótese de Lévi-Strauss não é que não existam preferências matrimoniais orientadas por consideraçóes de status, mas sim o fato de que nem os $i-e$ nem as unidades mais inclusivas, resultantes de sua agregação, podem ser tomados como grupos de fronteiras definidas e estáveis, capazes de operar coordenadamente da maneira suposta pela hipótese. Como mostraram os estudos de povos amazônicos com sistemas de parentesco "dravidiano", é a conceituação da aliança como uma relação entre segmentos pré-constituídos (fundados na linearidade ou num outro princípio normativo equivalente) que precisa ser aqui repensada.

A adesão de Lévi-Strauss ao modelo de segmentação dos salesianos não é incondicional, e ele continuará a insistir sobre a variedade de leituras legítimas do modelo nativo (1974[1956], p. 156-63; 1973, p. 94). O destaque que a hipótese da endogamia assume nos anos 1950 explica-se pela construção do multidualismo centro-brasileiro como um 
M. C. de Souza \& C. Fausto. Reconquistando o campo perdido...

fenômeno de travestimento exogâmico de realidades endogâmicas. Essa construção está ligada à elaboração conceitual das SEP e, em particular, à problemática da integração social que permeia o livro, no qual aparece inicialmente na distinção entre "endogamia verdadeira" (a recusa em reconhecer a possibilidade de casamento além dos limites da "cultura") e "endogamia funcional", contrapartida positiva da injunção exogâmica (Lévi-Strauss, 1967[1949], p. 54). A ameaça à integridade do tecido social surge quando as regras de casamento, pela concentração repetida de certas alianças, distorcem as implicações da exogamia, convertendoa em endogamia (pseudo)verdadeira, recriando no interior do grupo a mesma fronteira que o separava do exterior. Essa ênfase no risco de involução endogâmica e desintegração do grupo em "subsociedades" (idem, p. 265) deriva da mesma concepção morfologista, do mesmo privilégio das "classes" sobre as "relações", que dificultaram a compreensão dos sistemas de tipo nambikwara (ver Coelho de Souza, 2002). A reflexão posterior de Lévi-Strauss sobre o multidualismo centro-brasileiro conduziu-o, contudo, a uma revisão importante do esquema das SEP e a uma reformulação crucial do problema do dualismo ameríndio.

Característico dos sistemas centro-brasileiros, o fenômeno do multidualismo confrontava o autor com uma situação aparentemente paradoxal: a saber, a disjunção entre a superelaboração institucional e o fraco valor funcional (isto é, matrimonial) do princípio dualista. À parte a disposição circular e a distinção entre o (semi)círculo de casas e a praça central, comum a todas as versões, os vários sistemas jê comportam fórmulas diversas de diferenciação, envolvendo uma multiplicidade de subdivisões sobrepostas não-coincidentes. Certos povos jê levam essa complicação a extremos, acumulando vários pares de metades, em geral ágamos e baseados em princípios divergentes. Mesmo no caso bororo que, com sua exogamia e matrilinearidade, se apresenta como um siste- 
Revista de Antropologia, São Paulo, USP, 2004, v. 47 no 1.

ma relativamente harmônico, essa harmonia vê-se perturbada por um sistema de inversões rituais que, nas palavras de Crocker,

stands the whole society on its head, in an almost literal sense, and makes the Bororo ultimately much more Gêelike than they initially appear. (1979, p. 251)

Essas inversões bororo chamaram desde cedo a atenção de LéviStrauss, que, como vimos, procurou dar conta delas em termos da combinação entre diferentes estruturas de reciprocidade, e, em particular, da imposição de um dualismo aparente sobre um sistema triádico primitivo fundamental (1974[1952b], p. 143 e 145; 1984). Os sistemas jê parecer-lhe-ão passíveis de mesmo tratamento. Racionalização de dificuldades postas por configurações híbridas baseadas na combinação de estruturas de troca contraditórias, os modelos de que se valem os indígenas no Brasil central, e sua linguagem institucional (isto é, os sistemas de classes em que estes modelos se exprimem), esconderiam, sob seu dualismo e simetria ostensivos, uma organização triádica e assimétrica mais fundamental. Essa conclusão levará Lévi-Strauss a anunciar a necessidade de revisão da distinção entre troca restrita e troca generalizada. Reputando-a próxima demais das classificaçóes indígenas, ele sugerirá a necessidade de tratar a troca restrita como caso particular da troca generalizada, no qual, todavia,

même ce cas particulier n'est jamais complètement réalisé dans l'experience, sinon sous forme de rationalisation imparfaite de systèmes qui restent irréductibles à un dualisme, sous les espèces duquel ils essayent vainement de se représenter. (1974[1956], p. 167) 
M. C. de Souza \& C. Fausto. Reconquistando o campo perdido...

Essa conclusão é acompanhada de uma análise sofisticada do multidualismo, em que são determinadas as implicações de seus diferentes esquemas formais e as relações entre eles; análise que se desdobrará em um dos argumentos mais elusivos de Lévi-Strauss: o de que as organizações dualistas não existem. Esta tese, que visa inicialmente ao "esquema dualista” em geral, converter-se-á em uma hipótese sobre o dualismo ameríndio em particular que, inspirando muito da etnologia americanista contemporânea, revela a força da intuição etnográfica de LéviStrauss - e aquilo que ele deve aos índios.

\section{Dualismo concêntrico e diametral}

O artigo "Les organisations dualistes existent-elles?" abre-se com um contraste entre dois planos de aldeia winnebago, fornecidos por informantes nativos, em que a oposição entre estrutura diametral e estrutura concêntrica remete a duas conceitualizações alternativas de uma mesma organização, complexa demais para ser formalizada em um modelo único (LéviStrauss, 1974[1956], p. 149-50). O problema é o mesmo posto pela diversidade das versões disponíveis da estrutura social bororo: "racionalizações imperfeitas", os modelos duais têm sempre de desdobrar-se para recuperar aquilo que cada aplicação sua deixa escapar. Entretanto, a crítica levistraussiana não se limita a uma denúncia dos modelos nativos como simples "cortinas de fumaça" (pace Maybury-Lewis, 1989b, p. 104). É sempre possível evocar passagens contraditórias de Lévi-Strauss sobre o estatuto de modelos conscientes, ainda que seu interesse por estes como "contribuição teórica" tenha certamente aumentado com o tempo (ver 1966, p. 15). Seja como for, o artigo de 1956 destaca-se pela atenção que presta a tais "racionalizações": recusando-se a adjudicar entre soluções alternativas, propõe-se a tomá-las todas em conta e determinar sua relação. 
Revista de Antropologia, São Paulo, USP, 2004, v. 47 No 1.

O caso crucial é, outra vez, o Bororo, cujas anomalias e contradições serão analisadas agora por meio da determinação das propriedades formais de dois tipos de dualismo: o diametral e o concêntrico. $\mathrm{O}$ autor mostra de que modo uma estrutura diametral, como a que divide uma aldeia circular em duas metades, implica uma dicotomia simétrica e equilibrada do domínio considerado, e uma estrutura concêntrica, como a que opõe a praça central (pública) e a periferia das habitações (domésticas), uma oposição entre termos desiguais, uma vez que estes se apresentam "ordonnés par rapport à un même terme de référence: le centre" (1974[1956], p. 155). O contraste estabelece as bases para uma tipologia das estruturas dualistas (e não das organizações dualistas, note-se) em que as formas diametral-simétrica, de um lado, e concêntrico-hierárquica, de outro, são os pólos entre os quais se dispóem as estruturas diametrais assimétricas (idem), que, com sua misteriosa combinação de hierarquia e reciprocidade, preocupavam Lévi-Strauss desde 1944. Estas últimas descrevem a maioria dos sistemas de metades existentes (geralmente designadas por contrastes do tipo superior/inferior, forte/fraco etc.), mas seu estatuto difere do das duas primeiras, na medida em que a assimetria não decorre, ao contrário da estrutura concêntrica, de sua "natureza": sua posição intermediária corresponderia a uma solução de compromisso entre os dois pólos.

Já de um ponto de vista mais amplo, que considere a relação entre o dualismo e as formas de organização não-dualistas, são as próprias estruturas concêntricas que ocupam uma posição intermediária. Diádicas como as estruturas diametrais, mas assimétricas, elas seriam virtualmente ternárias, pois envolvem sempre a referência a um terceiro termo: não apenas ao centro que hierarquiza, mas também ao exterior para o qual se abrem. Enquanto para as estruturas diametrais esse exterior constitui um elemento não pertinente (criando a "ilusão de um sistema fechado"), no caso do dualismo concêntrico ele se apresenta como um prolonga- 
M. C. de Souza \& C. Fausto. Reconquistando o campo perdido...

mento da estrutura original, que estaria para o círculo periférico assim como este está para o círculo central (Lévi-Strauss, 1974[1956], p. 168). Esse ternarismo confere ao dualismo concêntrico propriedades dinâmicas: portadoras de um "triadismo implícito", tais estruturas fariam a mediação entre o dualismo estático de tipo diametral e as estruturas abertamente triádicas.

As noções de dualismo concêntrico e diametral serão fartamente utilizadas pelos estudiosos subseqüentes dos Jê, a partir do Projeto HarvardMuseu Nacional (ver especialmente DaMatta, 1976; Seeger, 1977; 1989). Mais tarde, a dialética desses esquemas, com suas implicações dinâmicas, servirá de modelo formal para a síntese de Viveiros de Castro sobre o dravidianato amazônico (Viveiros de Castro, 1993; Viveiros de Castro \& Fausto, 1993). O dualismo concêntrico, em particular, evocar-lhe-á um outro modelo de oposição, a oposição hierárquica dumontiana e a noção de englobamento do contrário, que vão ter um papel central nesses trabalhos. Viveiros de Castro irá sugerir que, nos sistemas dravidianos amazônicos (dos quais a mônada endogâmica guianesa aparece como caso típico), ao dualismo diametral da distinção afinidade e consangüinidade sobrepõe-se uma estrutura escalar e cromática, na qual a distância socioespacial organiza o campo social total e interfere na classificação terminológica, redefinindo a relação entre afinidade e consangüinidade: "En Amazonie, l'opposition affinitélconsanguinité est hiérarchique, et non pas équistatutaire ou distinctive" (Viveiros de Castro \& Fausto, 1993, p. 149); o dualismo diametral da classificação social egocentrada se dobra ao concentrismo e à lógica cromática do contínuo.

Viveiros de Castro forneceu o modelo formal daquilo que outros autores haviam descrito etnograficamente (em particular, Albert, 1985) para as relações intercomunitárias na Amazônia. Ao propor uma hierarquia (de valor) entre exterior e interior, articulou, ainda, o modelo sociológico ao cosmológico, aproximando os trabalhos sobre organização 
Revista de Antropologia, São Paulo, USP, 2004, v. 47 no 1.

social àqueles sobre a guerra e o xamanismo: todos exprimiriam uma mesma estrutura aberta e hierárquica, cujo vetor vai de fora para dentro, na qual a relação prototípica é a predação e o idioma relacional dominante é a afinidade (Viveiros de Castro, 1993). O conceito-chave aqui é o de "afinidade potencial" ${ }^{13}$ : a categoria em seu estado puro, valor nãomarcado e genérico, condição exterior e englobante do parentesco, distinta da afinidade matrimonial, que seria sua determinação e atualização na esfera subordinada em que se vê englobada pela consangüinidade. Essa "afinidade sem afins" remonta, mais uma vez e não por acaso, à afinidade fictícia que Lévi-Strauss viu em operação entre os bandos nambikwara.

A dialética do concêntrico e do diametral fornecerá também uma chave para a conceitualização da dinâmica histórica: "le gradient de la distance est le terrain par excellence de l'interaction entre structure et histoire" (Viveiros de Castro \& Fausto, 1993, p. 146) ${ }^{14}$. Mas seu dinamismo intrínseco já está claro no artigo de 1956, gerando a pluralidade de modelos (nativos), freqüentemente antitéticos, que se justapõem ou se sucedem porque só podem afirmar-se desta maneira: desdobrando-se, no espaço e no tempo, por justaposiçãa e por substituição. O contraste entre estruturas concêntricas e diametrais capturou, assim, um aspectochave do dualismo ameríndio - sua instabilidade - apreendendo-a sob a forma de uma dualidade interna ao próprio princípio dualista, a mesma instabilidade que o conceito de transformação topológica irá descrever a partir de Mythologiques até Histoire de Lynx.

Que isso nem sempre tenha sido percebido deve-se, pelo menos em parte, às habituais dificuldades de comunicação entre as duas margens do Canal da Mancha. A polêmica com Maybury-Lewis é a este respeito instrutiva (além de importante historicamente, pois constituiu o pano de fundo teórico do projeto de pesquisa coordenado por este último nos anos 1960 e 1970, que representou um avanço decisivo no desen- 
M. C. de Souza \& C. Fausto. Reconquistando o campo perdido...

volvimento da etnologia sul-americana). As duas críticas principais que Maybury-Lewis dirige à teoria das organizações dualistas de Lévi-Strauss são, primeiro, a de que, presa à problemática da reciprocidade, define de modo excessivamente estreito seu objeto, priorizando indevidamente a organização social e a dimensão matrimonial; segundo, a de que é uma teoria incapaz de apreender a historicidade das sociedades a que se aplica. Reduzindo a troca a uma instituição e o dualismo a uma representação, Maybury-Lewis priva-se da possibilidade de compreender a conexão entre as duas coisas e de tirar proveito daquela que foi a principal lição que os índios ensinaram a Lévi-Strauss: a potência da afinidade e sua realização como história.

\section{Dualismo: nem instituição nem representação}

A primeira crítica de Maybury-Lewis, de que Lévi-Strauss subordinara indevidamente o problema do dualismo à reciprocidade (1960; 1989a; 1989b), ignora a insistência deste último na distinção entre a organização dualista como instituição (metades) e o dualismo como esquema conceitual, suscetível de ser aplicado em uma diversidade de contextos "et qui pourrait même être universel” (Lévi-Strauss, 1962, p. 73). Essa distinção embasa aqui a aplicação de um procedimento característico da construção do objeto no estruturalismo: a dissolução do fenômeno em favor de sua determinação enquanto atualização contingente de uma estrutura de possíveis (que permanece aqui uma estrutura de reciprocidade). A crítica de Maybury-Lewis revela sua dificuldade em entender que a "reciprocidade" levistraussiana é ela mesma uma estrutura mental universal e não uma instituição particular, enquanto o princípio dualista "n'est lui-même qu'une modalité du principe de réciprocitê" (Lévi-Strauss, 1967[1949], p. 97). Identificando esse princípio à sua expressão matri- 
Revista de Antropologia, São Paulo, USP, 2004, v. 47 no 1.

monial institucional (a exogamia de metades), Maybury-Lewis (1960) não tem outra alternativa senão vê-lo como manifestação particular e contingente de uma outra coisa: o dualismo convertido na propensão a "pensar por antíteses". A distinção entre organizações dualistas e esquema dualista converte-se em sua leitura numa distinção entre dualismo "social" e dualismo "simbólico".

Para Lévi-Strauss, entretanto, trata-se sempre de estruturas de reciprocidade, isto é, de troca, ainda que estas não se restrinjam ao plano matrimonial. Como esclareceria em seguida, ele estava em busca de uma interpretação "generalisée de tous les phénomènes du dualisme" (1973, p. 91), que, como vimos, o leva a propor que os diversos dualismos sociológicos (com ou sem metades, sejam estas exógamas ou não) "supõem e recobrem" estruturas de aliança não-dualistas, isto é, triádicas (idem, p. 91-2). Se isso indica que a conexão entre dualismo "social" e aliança só pode ser indireta, é porque a reciprocidade não se reduz para LéviStrauss (pace Maybury-Lewis, 1960; 1989b) a um princípio de equilíbrio nas transações matrimoniais: afinal, "ce qu'une société 'dit' en termes de relations d'alliance, une autre société le 'dit' en termes d'organisation spatiale villageoise, une troisième en termes de représentations religieuses, etc." (Lévi-Strauss, 1973, p. 97), e, poderíamos, completar, em termos de seu estilo artístico. Afinal, não era essa a hipótese do autor para o grafismo kadiwéu que lhe aparece organizado em torno de uma dupla oposição ternarismo/binarismo, reciprocidade/hierarquia - assim como o plano da aldeia bororo? A arte gráfica dos Kadiwéu, povo Mbaya-Guaikuru que Lévi-Strauss conhecera ainda em 1935, no Mato Grosso, aparecialhe como solução no nível do simbólico para uma contradição que os Bororo haviam resolvido sociologicamente (1955, p. 168-9).

Para Maybury-Lewis, ao contrário, há uma oposição entre o social e o simbólico que não deriva da diferença entre um esquema e sua atualização, mas da distinção entre as esferas em que um tal esquema viria se 
M. C. de Souza \& C. Fausto. Reconquistando o campo perdido...

aplicar, a saber, entre cosmologia e organização social. Se uma tal distinção é ignorada por Lévi-Strauss (Maybury-Lewis, 1960), ela o é deliberadamente: "[É] precisamente sobre o valor absoluto de uma tal distinção que meu estudo sobre as organizações dualistas (...) abria um debate" (1973, p. 100); debate que seria plenamente assumido pela etnologia americanista em seu esforço para romper a separação entre os domínios do social e do cosmológico, da sociedade e da cultura, um ponto afirmado explicitamente por Overing Kaplan (1977; 1983-1984) e esposado por quase todos os especialistas da região. Empregada seja como método comparativo, seja na análise etnográfica, a noção de um esquema comum que se manifesta por meio de diferentes códigos sensíveis vai influenciar profundamente a etnologia amazônica a partir dos anos 1970 e libertá-la do tipologismo funcionalista.

Em Histoire de Lynx, o próprio Lévi-Strauss retornaria ao problema, agora sob a forma do contraste entre o florescimento institucional do dualismo centro-brasileiro e a elaboração mítica do mesmo tema entre os Tupi (1991, p. 315-6). A análise do dualismo dá lugar aí a um desenvolvimento suplementar. No capítulo dedicado ao problema da "idéologie bipartite des indiens", após se dissociar de uma interpretação das organizações dualistas como expressão da "natureza binária do pensamento humano", Lévi-Strauss escreve:

Je constate seulement que des peuples qui occupent une aire géographique immense, certes, mais circonscrite, ont choisi d'expliquer le monde sur le modèle d'un dualisme en perpétuel déséquilibre dont les états successifs s'emboîtent les uns dans les autres: dualisme qui s'exprime de façon cohérante tantôt dans la mythologie, tantôt dans l'organisation sociale, tantôt dans les deux ensembles. (Lévi-Strauss, 1991, p. 316) 
Lévi-Strauss crê agora encontrar uma problemática particularmente ameríndia, na qual antes vira a expressão do princípio universal da reciprocidade (e Maybury-Lewis, uma propensão igualmente universal a pensar por antíteses). Pode-se ler aqui a passagem de uma teoria geral da reciprocidade a uma teoria "restrita" do dualismo ameríndio, que representaria, a partir de Mythologiques, uma reamerindianização da obra de Lévi-Strauss. Nosso argumento, porém, é que, de um extremo a outro dessa trajetória, do cunhadio nambikwara ao multidualismo centro-brasileiro, e da troca matrimonial ao mito, se sente a força de uma mesma inspiração: "l'identité constitue un état révocable ou provisoire, elle ne peut pas durer” (1991, p. 305). Inspiração etnográfica, suscitada, pelo menos em parte, pelo lugar que a socialidade e o pensamento indígenas conferem à categoria da afinidade, por meio da qual se abrem para a alteridade e para o tempo.

\section{Dualismo em perpétuo desequilíbrio e a abertura ao outro}

Durante a década de 1970 e 1980, a etnologia amazônica dedicou-se à crítica aos modelos africanos da antropologia social britânica, cuja inadequação para descrever as sociedades da região havia sido apontada pelos jeólogos na década anterior, e à construção de uma linguagem conceitual adequada à descrição das realidades indígenas locais (ver especialmente Carneiro da Cunha, 1977; 1978; Seeger et al., 1979; e os trabalhos reunidos em Overing Kaplan, 1977). Já indicamos como a teoria da aliança foi ambientada ao contexto amazônico e como o tema do "cunhadio" foi desenvolvido na direção de uma metafísica da afinidade e daquilo que Viveiros de Castro chamou de economia simbólica da alteridade (1996b). Essa dialética da identidade e da alteridade herança por certo da problemática do "même et l'autre" na filosofia 
M. C. de Souza \& C. Fausto. Reconquistando o campo perdido...

francesa do século XX e da tentativa de superar a filosofia do Sujeito encontrou solo fértil na Amazônia, constituindo-se em um de seus temas mais profícuos. A recusa de uma definição identitária do $\mathrm{Si}$ - na qual os termos de uma relação preexistem à própria relação - não é, no entanto, simples atitude teórica de rejeição a certa tradição filosófica ou mera aplicação de lições da fonologia estrutural. Como já intuíra LéviStrauss em 1943, ela possui uma afinidade eletiva com as realidades ameríndias. É isso que Histoire de Lynx procurará consolidar, mostrando, por meio da análise das suas diferentes concepções da gemelidade, que a relação entre identidade e diferença põe-se no mundo ameríndio de forma diversa daquela do pensamento europeu (Lévi-Strauss, 1991, p. 302-7, 316).

Ao problema posto pela gemelidade - "la dualité peut-elle se résorber dans l'image approchée de l'unité par quoi on la représente, ou offre-t-elle un caractère irréversible, à tel point que l'écart minimal entre ses termes doivent fatalement s'élargir?" (Lévi-Strauss, 1991, p. 300) -, os nativos do Novo Mundo teriam preferido dar respostas intermediárias, e entre a contraditoriedade e a identidade teriam escolhido a instabilidade. A identidade aparece, pois, como um estado revogável e provisório: nem mesmo gêmeos podem ser idênticos. A identidade pura é uma condição inalcançável ou, em alguns casos, não desejável pois igualada à morte ${ }^{15}$. O princípio do desequilíbrio encontra-se no interior do par, na assimetria entre os dois termos (no caso, a desigualdade relativa entre os gêmeos), que instaura uma dinâmica particular de desdobramentos ou encaixamentos regressivos, tal como expresso por exemplo no diagrama do mito tupinambá de diferenciações sucessivas em que um dos pólos sempre se biparte em um novo par (idem, p. 76). Obrigado a, etapa após etapa, desdobrar assim os termos da oposição inicial, o modelo do dualismo em perpétuo desiquilíbrio presta-se portanto a uma leitura de tipo fractal, no qual a mesma forma repete-se em diferentes escalas. Essa 
Revista de Antropologia, São Paulo, USP, 2004, v. 47 no 1.

representação coincide (e não por acaso) com a caracterização do dinamismo próprio ao dualismo concêntrico.

Esse ponto é enunciado nas formulações mais recentes de Viveiros de Castro. Ao refrasear o conceito de afinidade potencial, tomando agora distância em relação à problemática da totalidade implicada na linguagem dumontiana (Viveiros de Castro, 2002), o autor faz um movimento paralelo ao que leva Lévi-Strauss da crítica do dualismo em 1956 ao elogio do dualismo em perpétuo desequilíbrio em 1991. Também em seu caso, vemos a dialética do concêntrico e do diametral, o jogo do triadismo e do dualismo, reaparecer sob a forma de uma estrutura assimétrica constituída de dualismos sucessivos; nesta estrutura, a afinidade potencial aparece como "dado genérico, fundo virtual contra o qual é preciso fazer aparecer uma figura particular de socialidade consangüínea” (idem, p. 423-4), e a consangüinidade (o parentesco no sentido estrito) deve por sua vez ser deliberadamente fabricada, extraída deste fundo virtual, "mediante uma diferenciação intencional e construída da diferença universalmente dada" (idem). Essa extração, entretanto, sugere o autor, produz necessariamente "mais afinidade", uma vez que o "potencial de diferenciação é dado pela afinidade: diferenciar-se dela é afirmá-la por contra-efetuação" (idem, p. 432). O diagrama que Viveiros de Castro oferece dessa estrutura, que descreve como de "atualização" e "contra-efetuação" da afinidade, estrutura "estruturante", "que descreve uma morfogênese, não uma morfologia” (idem, p. 433), corresponde explicitamente àquele com que Lévi-Strauss ilustra o dualismo recursivo do mito tupinambá em Histoire de Lynx (Lévi-Strauss, 1991, p. 76; Viveiros de Castro, 2002, p. 436 ss.).

Os dois aspectos mais mal-compreendidos da teoria levistraussiana do dualismo - de um lado, a natureza de seu objeto (nem instituição, nem representação), de outro, seu dinamismo - estão intimamente conectados, remetendo ambos ao valor da afinidade como esquema da 
M. C. de Souza \& C. Fausto. Reconquistando o campo perdido...

diferença nas sociocosmologias ameríndias. A maior parte dos críticos tendeu a ler a obra de Lévi-Strauss como redução do mundo dinâmico do vivido ao mundo estático das categorias puras e das oposições binárias, em vez de enfatizar aquilo que permite dotar de movimento os princípios e esquemas que encontramos sob a diversidade de fenômenos observados etnograficamente. Tal movimento parece-nos dominar não apenas a elaboração do problema do dualismo, como também a própria noção de estrutura transformacional das Mythologiques. Esta obra, verdadeiro experimento do método comparativo elaborado contra o rigor tipológico do comparativismo funcionalista, pode ser tomada ainda, conforme sugeriu recentemente Peter Gow, como nos oferecendo uma "specifically anthropological conceptualization of history" (2001, p. 13), na qual as transformaçōes diacrônicas sofridas pelo mito são interpretadas como permutações que procuraram responder à passagem do tempo e às mudanças históricas, de modo a manter a escala e o sentido do mundo vivido. Para que o mito possa "obliterar o tempo" e fornecer a ilusão quente de uma estabilidade fria, ele deve estar em contínua transformação, sendo, por definição, um objeto histórico que pode ser interrogado enquanto tal. Uma vez mais, estamos diante de uma instabilidade geradora de movimento. $\mathrm{O}$ que talvez explique por que, como se pergunta Lévi-Strauss,

au regard de la gémellité, des sociétés chaudes peuvent s'accommoder d'une philosophie froide, et que des sociétés froides - peut-être parce qu'elles le sontressentent le besoin d'une philosophie chaude. (1991, p. 316-7)

Por fim, em Histoire de Lynx Lévi-Strauss intui poder retornar às fontes filosóficas e éticas não apenas do dualismo ameríndio, mas também às suas próprias, que o haviam conduzido de Rousseau aos Nambikwara. A “ouverture à l'autre”, que é fonte de inspiração do dualismo ameríndio, 
é também a fonte que impulsionou Lévi-Strauss ao campo, que fez dele etnólogo e não filósofo, e que persiste hoje em sua impaciência com os destinos da antropologia, acossada, de um lado, pelo egotismo e, de outro, pelo medo em afirmar a diferença. Eis a face contemporânea do imperialismo que, ao rejeitar a diferença como exotismo, crê elevar moralmente outros povos por conceder a eles aquilo que a metrópole valoriza para si mesma. A boa antropologia, contudo, aquela que os ameríndios ensinaram a Lévi-Strauss, não tem medo da diferença mas dela se alimenta.

\section{Notas}

1 Esta é a versão ampliada de um texto a ser publicado em francês, cujo título é "Regagner le Terrain Perdu: Ce que Lévi-Strauss doit aux indiens". O título possui duplo sentido, difícil de se preservar na tradução para o português, pois se nossa expressão militar é "reconquistar o terreno perdido", designamos a pesquisa etnográfica como "campo" (e não "terreno" à maneira dos franceses).

2 Nimuendaju trabalhava há mais de uma década com povos de língua Jê do Brasil Central, sobre os quais publicaria três importantes monografias (1939, 1942, 1946), editadas graças à colaboração com Robert Lowie.

3 O primeiro encontro de Lévi-Strauss com índios brasileiros deu-se no norte do Paraná, em 1935, durante uma breve visita aos Kaingang (Jê meridionais). De novembro de 1935 a março de 1936, ele visitou os Kadiwéu, na fronteira com o Paraguai, e os Bororo, no Mato Grosso, em uma expedição de maior fôlego, cujos resultados etnográficos (notadamente, o artigo sobre os Bororo e a exposição para o Musée de l'Homme) permitiram-lhe ser reconhecido como etnólogo. Com isso, pôde obter recursos para a missão realizada entre maio e novembro de 1938, que o levou aos Nambikwara e aos Tupi-Kawahib do Rio Machado (Peixoto, 1998).

4 Ver as críticas de Aspelin $(1976,1979)$ e Price (1978), bem como as respostas de Lévi-Strauss $(1976,1978)$. 
M. C. de Souza \& C. Fausto. Reconquistando o campo perdido...

5 Ver também o texto de encerramento da conferência Man, the Hunter (1968), "On the concept of primitiveness", no qual Lévi-Strauss volta à questão, desta feita com um novo adepto (Lathrap 1968).

6 A discussão sobre o caráter regressivo ou não de povos caçadores-coletores na Amazônia - se eram ou não populações horticultoras que se dessedentarizaram (em geral por causa de intrusões, violências e epidemias pós-conquista) - foi retomada por pesquisas posteriores (Lathrap, 1968; Martin, 1969; Clastres, 1972; Balée, 1994). Sobre a possibilidade de terem existido caçadores-coletores "à part entière" na floresta tropical, ver Lévi-Strauss (1974[1952], p. 123), Bailey et al. (1989), Bailey \& Headland (1991), Headland (1987). Para uma análise crítica da discussão, ver Good (1995) e Fausto (2001).

7 Ver, por exemplo, Posey (1986) sobre o manejo de áreas transicionais de cerrado e floresta entre os Kayapó, e Flowers (1994) sobre os Xavante.

8 Coordenado por Maybury-Lewis, esse projeto, que reuniu, nos anos 1960, pesquisadores brasileiros e americanos, graças a um convênio entre Harvard e o Museu Nacional do Rio de Janeiro, retomou questôes postas pela análise levistraussiana do material jê de Nimuendaju. Os resultados téoricos e etnográficos do projeto, consolidados na coletânea Dialectical Societies (Maybury-Lewis, 1979), viriam a influenciar decisivamente não apenas o estudo dos povos centro-brasileiros como toda a etnologia sul-americanista.

9 Nos anos 1930, a etnografia bororo resumia-se a Von den Steinen (1894), Radin e Fric (1906), Cook (1907), Colbacchini (1925) e Baldus (1936), estudos ancorados, com exceção do penúltimo, em experiências tão ou mais breves que a de LéviStrauss.

10 Em 1936, Lévi-Strauss fala em quatro clãs numa metade, seis em outra, tomando aparentemente subdivisões por clãs independentes (1936, p. 270-1). Já em Tristes trópicos, Lévi-Strauss falará da divisão octogonal reportada pelos salesianos como "provável no passado", mas diluída com o tempo pelos processos de extinção e subdivisão clânica: "a situação empírica é portanto confusa" (1955, p. 252).

11 Os clās Bado Jeba ("construtores da aldeia"), que detêm os títulos de chefia, pertencem à metade norte, Exerae. Essa hierarquia seria ambivalente, pois os termos Exerae e Tugarege, segundo Lévi-Strauss, podiam ser associados, respectivamente, aos significados "fraco" e "forte", uma interpretação que é contestada entretanto pelos salesianos. 
12 Crocker acabará por lhe dar alguma razão: seus informantes "concordaram com os de Lévi-Strauss, dizendo que para alguns propósitos a aldeia era, antigamente, dividida numa parte 'superior' e noutra 'inferior' por um eixo norte-sul pelo meio da aldeia. Essa divisão, certamente, não vigora entre os Bororo atuais” (1969, p. 57-8, n. 6).

13 Ver Viveiros de Castro (2002, p. 412-3), para uma reconsideração do batismo desse conceito, que Taylor, invertendo a terminologia original do autor, sugeriu recentemente chamar "virtual" ou "metaafinidade" (2000, p. 312, n. 6), e a que Descola (1993, p. 183) se referira como "afinidade ideal".

14 Esse foi um aspecto importante do esforço teórico de vários autores brasileiros que procuraram nos anos 1980 e 1990 especificar etnograficamente aquilo que Sahlins (1985) chamou de "estruturas performativas". Ver os artigos na coletânea organizada por Viveiros de Castro (1995).

15 Essa concepção tem conseqüências importantes para a questão da identidade pessoal e coletiva, que marca uma diferença central entre a etnologia amazônica de orientação estruturalista e aquela inspirada por uma antropologia da identidade.

\section{Bibliografia}

ALBERT, B. 1985

Temps du sang, temps de cendres. Représentations de la maladie, système rituel et espace politique chez les Yanomami du sud-est (Amazonie brésilenne), tese, Laboratoire d'Ethnologie et de Sociologie Comparative, Université de Paris X.

ALBISETTI, C. 1948

"Estudos complementares sobre os Bororo orientais", Contribuiçōes missionárias, Publicações da Sociedade Brasileira de Antropologia e Etnologia, 2-3.

ALBISETTI, C. E. \& VENTURELLI, A. J.

1962 Enciclopédia Bororo, Campo Grande, Museu Regional Dom Bosco.

1969 Enciclopédia Bororo II, Campo Grande, Museu Regional Dom Bosco.

1976 Enciclopédia Bororo III, Campo Grande, Museu Regional Dom Bosco. 
M. C. de Souza \& C. Fausto. Reconquistando o campo perdido...

ARHEM, K.

1993

"Ecosofia Makuna", in CORREA, F. (org.), La selva humanizada: ecología alternativa en el Trópico Húmedo colombiano, Bogotá, Instituto Colombiano de Antropología/Fondo FEN Colombia/Fondo Editorial CEREC, p. 109-26.

ASPELIN, P.

1976

"Nambikwara Economic Dualism: Lévi-Strauss in the Garden, Once Again", Bijdragen tot de Taal-Land-en Volkenkunde, vol. 132(1): 1-32.

1979 "The Ethnography of Nambikwara Agriculture", Bijdragen tot de Taal- Landen Volkenkunde, vol. 135(1): 18-58.

BAILEY, R. et al.

"Hunting and Gathering in Tropical Rain Forest: Is It Possible?", American Anthropologist, vol. 91(1): 59-82.

BAILEY, R. \& HEADLAND, T.

1991

"Have Hunter-Gatherers Ever Lived in Tropical Rain Forest Independently of Agriculture?”, Human Ecology, vol. 19(2): 115-286.

BAUDUS, $\mathrm{H}$.

1936

Ensaios de etnologia brasileira, São Paulo.

BALÉE, W.

Footprints of the Forest: Ka'apor Ethnobotany, New York, Columbia University Press.

BECKER, B.

Xingu Society, Chicago, PhD Thesis, Department of Anthropology, University of Chicago.

CAIUBY NOVAES, $S$.

1986 Mulheres, homens e heróis: dinâmica e permanência através do cotidiano da vida Bororo, São Paulo, Universidade de São Paulo.

CARNEIRO DA CUNHA, M.

1977

"Espace funéraire, eschatologie et culte des ancêtres: encore le problème des paradigmes africains", in OVERING KAPLAN, J. (org.), Social time and social 
space in Lowland South American societies, Actes du XLII Congrès International des Américanistes (Paris, 1976), Paris, Société des Américanistes, p. 277-95.

1978 Os mortos e os outros. Uma análise do sistema funerário e da noção de pessoa entre os indios Krahó, São Paulo, Hucitec.

CLASTRES, P.

1972

Chronique des Indiens Guayaki, Paris, Plon.

COELHO DE SOUZA, M.

2002 Otraço e o círculo: o conceito de parentesco entre os Jê e seus antropólogos, Rio de Janeiro, tese, PPGAS/MN/UFRJ.

COLBACCHINI, A.

1925 Bororo Orientali “Orarimudogue” del Matto Grosso (Brasile), Turin.

COLBACCHINI, A. \& ALBISETTI, C.

1942 Os Bororo orientais orarimogodógue do planalto oriental de Mato Brosso, São Paulo, Cia. Editora Nacional.

COOK, W. A.

1907

The Bororo Indians of Mato Grosso, Brazil, Smithsonian Miscellous Collections.

CROCKER, J. C.

1967 The Social Organization of the Eastern Bororo, Cambridge, MA, PhD Thesis, Harvard University.

1969 "Reciprocity and hierarchy among the Eastern Bororo", Man, vol. 4(1): 44-58.

1979 "Selves and alters among the Eastern Bororo", in MAYBURY-LEWIS, D. (org.),

Dialectical Societies: The Gê and Bororo of Central Brazil, Cambridge, MA, Harvard University, p. 249-300.

DAMATTA, R.

1976 Um mundo dividido: estrutura social dos indios Apinayé, Petrópolis, Vozes.

DESCOLA, P.

1981

"From scattered to nucleated settlement: a process of socioeconomic change among the Achuar", N. W. (ed.), Cultural Transformation and Ethnicity in Modern Ecuador, Urbana, University of Illinois, p. 614-46. 
M. C. de Souza \& C. Fausto. Reconquistando o campo perdido...

1986 La Nature Domestique: symbolisme et praxis dans l'écologie des Achuar, Paris, Maison des Sciences de l'Homme.

1992 "Societies of nature and the nature of society", in KUPER, A. (org.), Conceptualizing Society, Londres, Routledge, p. 126-97.

1993 "Les affinités sélectives: alliance, guerre et prédation dans l'ensemble jivaro", L'Homme, vol. XXXIII(2-4): 171-90.

2001 "Leçon Inaugural (faite le Jeudi 29 mars 2001)", Chaire d'Anthropologie de la Nature, Paris, Collège de France.

DESCOLA, P. \& TAYLOR, A.-C.

1993 "Introduction", L'Homme, vol. XXXIII(2-4): 13-24.

DUMONT, L.

1971

[1953]1975

[1957]1975

1983

Introduction a deux théories d'anthropologie sociale, Paris, Éditions de l'École des Hautes Études en Sciences Sociales.

"Le vocabulaire de parenté dravidien comme expression du mariage", in Dravidien et Kariera: l'alliance de mariage dans l'Inde du Sud et en Australie, Paris, Mouton, p. 85-100.

"Hiérarchie et alliance de mariage dans la parenté de l'Inde du Sud", in Dravidien et Kariera: l'alliance de mariage dans l'Inde du Sud et en Australie, Paris, Mouton, p. 7-83.

"Stocktaking 1981: affinity as value", in (org.), Affinity as a Value: marriage alliance in South India with comparative essays on Australia, Chicago/ London, The University of Chicago, p. 145-71.

FABIAN, S. M.

Space-time of the Bororo of Brazil, Gainesville, University Press of Florida.

FAUSTO, C.

2001

Inimigos fieis: história, guerra e xamanismo na Amazônia, São Paulo, Edusp.

FLOWERS, N. M.

1994

"Subsistence strategy, social organization, and warfare in Central Brazil in the context of European penetration", in ROOSEVELT, A. C. (org.), Amazonian Indians from Prehistory to the Present, Tucson, University of Arizona, p. 249-70. 
GOOO, K.

1995

"Yanomani of Venezuela: foragers or farmers - which came first?", in SPONSEL, L. E. (ed.), Indigenous peoples and the future of Amazonia: an ecological anthropology of an endangered world, Tucson, University of Arizona, p. 113-20.

GOW, P.

2001

An Amazonian Myth and Its History, Oxford, Oxford University.

GROSS, D.

1975 "Protein Capture and Cultural Development in the Amazon Basin", American Anthropologist, vol. 77(3): 526-49.

HILL, K. \& HAWKES, K.

1983 "Neotropical Hunting Among the Aché of Eastern Paraguay", in HAMES, R. \& VICKERS, W. (eds.), Adaptative Responses of Native Amazonians, New York, Academic Press, p. 113-35.

HAWKES, K.; HILL, K. \& O’CONNEL, J.

1982 "Why hunters gather: optimal foraging and the Aché of Eastern Paraguay", American Ethnologist, vol. 9(2): 379-98.

HEADLAND, T.

“The Wild Yam Question: How Well Could Independent Hunter-Gatherers Live in a Tropical Rain Forest Ecosystem?, Human Ecology, vol. 15: 463-91.

LATHRAP, D. W.

1968 "The 'hunting' economies of the tropical forest zone of South America: an attempt at historical perspective", in LEE, R. B. \& DE VORE, I. (orgs.), Man the Hunter, Chicago, Aldine Publishing Company, p. 23-9.

LÉVI-STRAUSS, C.

1936 "Contribution a l'étude d'organisation sociale des indiens bororo", Journal de la Société des Américanistes, vol. 28: 269-304.

1943 "The social use of kinship terms among Brazilian indians", American Anthropologist, vol. 45: 398-409. 
M. C. de Souza \& C. Fausto. Reconquistando o campo perdido...

1944a "The social and psychological aspect of chieftainship in a primitive tribe: the Nambikwara of North-Western Mato Grosso", Transactions of the New York Academy of Sciences (Series II), vol. 7(1): 16-32.

$1944 \mathrm{~b} \quad$ "On dual organization in South America". America Indigena, vol. 4: 37-47.

1944c "Reciprocity and hierarchy", American Anthropologist, vol. 46: 266-8.

1946

1947

"The Name of the Nambikwara", American Anthropologist, vol. 48(1): 139-40. "La théorie du pouvoir dans une société primitive", in GOTTMANN, J. \& MIRKINE-GUETZÂEVITCH, B., Les doctrines politiques modernes, New York, Brentano's, p. 41-63.

1948a La vie familiale et sociale des indiens Nambikwara, Paris, Société des Americanistes.

1948b "Tribes of the Right Bank of the Guaporé River", in STEWARD, J. (ed.), Handbook of South American Indians, vol. 3, Washington, Smithsonian Institution/Bureau of American Ethnology, Bulletin 143, p. 371-80.

1955 Tristes tropiques, Paris, Plon.

1962 Le totémisme aujourd'hui, Paris, Presses Universitaires de France.

1964 Mythologiques I: le cru et le cuit, Paris, Plon.

1966 "The future of kinship studies (The Huxley Memorial Lecture 1965)", in (org.), Proceeding of the Royal Anthropological Institute of Great Britain and Ireland for 1965, London, RAI, p. 13-22.

1967[1949] Les structures élémentaires de la parenté, Paris/La Haye, Mouton \& CO.

1968 "The concept of primitiveness", in LEE, R. B. \& DEVORE, I. (org.), Man the Hunter, Chicago, Aldine Publishing Company, p. 349-52.

1973 "Sens et usage de la notion de modèle", in Anthropologie Structurale II, Paris, Plon, p. 89-101.

1974[1949] "Le sorcier et sa magie", Anthropologie structurale, Paris, Plon, p. 183-203.

1974[1952a] "La notion d'archaïsme en ethnologie", in Anthropologie Structurale, Paris, Plon, p. 113-32.

1974[1952b] "Les structures sociales dans le Brésil central et oriental", in Anthropologie Structurale, Paris, Plon.

1974[1956] "Les organisations dualistes existent-elles?", in Anthropologie structurale, Paris, Plon.

1974[1958] "La notion de structure en ethnologie", in (org.), Anthropologie Structurale, Paris, Plon, p. 303-51.

1976[1942] "Guerra e comércio entre os índios da América do Sul", in SCHADEN, E. (ed.), Leituras de etnologia brasileira, São Paulo, Cia. Editora Nacional, p. 325-39. 
Revista de Antropologia, São Paulo, USP, 2004, v. 47 no 1.

1984

$1991 \mathrm{a}$

1993

LIMA, T. S.

1996
"État actuel des études bororo", Paroles Données, Paris, Plon, p. 181-5.

Histoire de Lynx, Paris, Plon.

"Un autre regard”, L'Homme 126-128, vol. XXXIII(2-4): 7-10.

1941

"A note on the northern Gê tribes of Brazil", American Anthropologist, vol. 43: 188-96.

MARTIN, M. K.

1969

"South American Foragers: a Case Study in Cultural Devolution", American Anthropologist, vol. 71: 243-60.

MAYBURY-LEWIS, D.

1960 "The analysis of dual organizations: a methodological critique", Bijdragen tot de Taal-Land-en Volkenkunde, vol. 116(1): 17-44.

1967 Akwe-Shavante society, Oxford, Clarendon.

1979 (org.), Dialectical Societies: The Gê and Bororo of Central Brazil, Cambridge, MA, Harvard University.

1989a "Introduction. The Quest for Harmony", in MAYBURY-LEWIS, D. \& ALMAGOR, U. (org.), The Attraction of Opposites. Thought and Society in the Dualistic Mode, Ann Arbor, The University of Michigan, p. 1-18.

1989 b "Social theory and social practice: binary systems in central Brazil", in MAYBURY-LEWIS, D. \& ALMAGOR, U. (org.), The Attraction of Opposites: Thought and society in the dualistic mode, Ann Arbor, University of Michigan, p. $97-142$.

MEGGERS, B. J.

"Environment limitation on the development of culture", American Anthropologist, 56: 801-24.

1971 Amazonia: man and culture in a counterfaite paradaise, Chicago, AldineAltherton. 
M. C. de Souza \& C. Fausto. Reconquistando o campo perdido...

NIMUENDAJU, C.

1942 The Sherente, Los Angeles, Frederick Webb Hodge Anniversary Publication Fund.

1946 The Eastern Timbira, Berkeley, University of California.

[1939]1967 The Apinayé, The Netherlands, Oesterhout N. B.

OVERING KAPLAN, J.

1975 The Piaroa, a People of the Orinoco Basin: a Study in Kinship and Marriage, Oxford, Claredon.

1976 (org.), Social time and social space in Lowland South American societies, Actes du XLII Congrès International des Américanistes, Paris, Société des Américanistes.

1977 "Orientarion for paper topics \& Comments", in OVERING KAPLAN, J. (org.), Social time and social space in Lowland South American societies, Actes du XLII Congrès International des Américanistes, Paris.

1983-1984 "Elementary structures of reciprocity: a comparative note on Guianese, Central Brazilian, and North-West Amazon socio-political thought", Antropologica, vol. 59-62: 331-48.

PEIXOTO, F.

1998

"Lévi-Strauss no Brasil: a formação do etnólogo", Mana, Estudos de Antropologia Social, vol. 4(1): 79-107.

POSEY, D. A.

1986

"Manejo da floresta secundária, capoeiras, campos e cerrados (Kayapó)", in RIBEIRO, B. (org.), Suma etnológica brasileira 1, Petrópolis, Finep/Vozes.

PRICE, D.

1978

1981

"Real toads in imaginary gardens: Aspelin vs. Lévi-Strauss on Nambikwara nomadism", Bijdragen tot de Taal-, Land-en Volkenkunde, vol. 134(1): 149-61. "Nambikwara leadership Nambiquara geopolitical organization", American Ethnologist, vol. 8(4): 1-24.

RADIN, P. \& FRIC, V.

1906 "Contributions to the study of Bororo Indians", The Journal of the Royal Anthropological Institute of Great Britain and Ireland, vol. XXXVI: 382-406. 
RIVAL, L.

1998

2002

"Domestication as a historical and symbolic process: wild gardens and cultivated forests in the Ecuadorian Amazon", in BALÉE, W., Advances in Historical Ecology, New York, Columbia University, p. 232-50.

Trekking through history: the Huaorani of Amazonian Ecuador, New York, Columbia University.

RIVIÈRE, P.

1969 Marriage among the Trio: a Principle of Social Organization, Oxford, Claredon. 1973 The lowlands South America culture area: towards a structural definition, New Orleans.

ROOSEVELT, A.

1980 Parmana: pre-historic maize and manioc subsistence along the Amazon and the Orinoco, New York, Academic.

ROOSEVELT, A. C.

1993 "The Rise and Fall of the Amazon Chiefdoms", L'Homme 126-128, vol. 33(24): 255-83.

SAHLINS, M.

Islands of history, Chicago, The University of Chicago.

SEEGER, A.

"Fixed points on arcs in circles: the temporal processual aspect of Suyá space and society", in OVERING KAPLAN, J. (org.), Social Time and Social Space in Lowland South American societies, Actes du XLII Congrés International des Americanistes, Paris.

"Dualism: fuzzy thinking or fuzzy sets?", in MAYBURY-LEWIS, D. \& ALMAGOR, U. (org.), The Attraction of Opposites. Thought and Society in the Dualistic Mode, Ann Arbor, The University of Michigan, p. 191-208.

SEEGER, A.; DAMATTA, R. \& VIVEIROS DE CASTRO, E.

1979 "A construção da pessoa nas sociedades indígenas brasileiras", Boletim do Museu Nacional. Antropologia, vol. 32: 2-19. 
M. C. de Souza \& C. Fausto. Reconquistando o campo perdido...

STEWARD, J. H.

1950 "South American Cultures: an interpretative summary", in STEWARD, J. H. (org.), Handbook of South American Indians, Washington, Smithsonian Institution, p. 669-772.

STEWARD, J. \& FARON, L. C.

1959 Native Peoples of South America, New York, McGraw-Hill.

TAYLOR, A.-C.

$2000 \quad$ "Le sexe de la proie: représentations jivaro du lien de parenté", L'Homme, vol. 154-155: 309-34.

VIERTLER, R. B.

1976 As aldeias Bororo: alguns aspectos de sua organização social, São Paulo, Museu Paulista.

VIVEIROS DE CASTRO, E. B.

1993 "Alguns aspectos da afinidade no dravidianato amazônico", in CARNEIRO DA CUNHA, M. \& VIVEIROS DE CASTRO, E. B. (org.), Amazônia: etnologia e história indígena, São Paulo, Núcleo de História Indígena e do Indigenismo da USP/Fapesp, p. 149-210.

1995 (org.), Antropologia do parentesco: estudos amerindios, Rio de Janeiro, Editora da UFRJ.

1996a "Os pronomes cosmológicos e o perspectivismo ameríndio", Mana, Estudos de Antropologia Social, vol. 2(2): 115-44.

1996b "Images of nature and society in Amazonian ethnology", Annual Review of Anthropology, vol. 25: 179-200.

1998 "Cosmological deixis and Amerindian perspectivism", Journal of the Royal Anthropological Institute, vol. 4(3): 469-88.

2002 "Atualização e contraefetuação do virtual: o processo do parentesco", $A$ inconstância da alma selvagem e outros ensaios de antropologia, São Paulo, Cosac \& Naify, p. 401-56.

VIVEIROS DE CASTRO, E. B. \& FAUSTO, C.

1993 "La Puissance et l'Acte: la parenté dans les basses terres de l'Amérique du Sud", L'Homme, vol. XXXIII(2-4): 141-70. 
Revista de Antropologia, São Paulo, USP, 2004, v. 47 no 1.

VON DEN STEINEN, K.

1940[1894] Entre os aborígenes do Brasil Central, São Paulo, Departamento de Cultura.

ZERRIES, O.

1976[1963-1964] "Organização social e imagem do mundo entre índios brasileiros", in SCHADEN, E. (org.), Leituras de etnologia brasileira, São Paulo, Cia. Editora Nacional, p. 87-125.

WELPER, E. M.

2002 Curt Unkel Nimuendaju: um capítulo alemão na tradição etnográfica brasileira, dissertação, Rio de Janeiro, Programa de Pós-Graduação em Antropologia Social, Museu Nacional, UFRJ.

WÜST, I.

1998 "Continuities and Discontinuities: Archaeology and Ethnoarchaeology in the Heart of the Eastern Bororo Territory, Mato Grosso, Brazil", Antiquity, vol. 72: 663-75.

WÜST, I. \& BARRETO, C.

1999 "The Ring Villages of Central Brazil: A Challenge for Amazonian Archaeology", Latin American Antiquity, vol. 10(1): 3-23.

ABSTRACT: This article reconsiders Levi-Strauss' fieldwork in Brazil from the perspective of the ethnographic and theoretical debates generated by his Americanist work. It focus on the problem of dualism, accompanying its development since the early writings on the Bororo and the Nambikwara until The History of Lynx (1991). The article casts light on the central place of South American ethnographic material on Levi-Strauss' work, as well as on the relevence of his own contribution to contemporary ethnology.

KEY WORDS: structuralism, dualism, identity, indigenous peoples.

Aprovado em março de 2004. 